\title{
Optimisation of a Textile Process Using Taguchi Method
}

\author{
${\text { Akshay } \operatorname{Kumar}^{*}, 1 \text { and S. M. Ishtiaque }}^{2}$ \\ ${ }^{I}$ The Abhishek Industries Ltd, Trident Complex, Barnala, Punjab, India \\ ${ }^{2}$ Professor, Department of Textile Technology, Indian Institute of Technology, New Delhi- 110 016, India
}

\begin{abstract}
Taguchi Method is explained in brief and one of the textile processes, called spinning process, is optimised by using Taguchi method for manufacturing optimum packing density of different technologies yarns. The effect of process variables like: lap hank, card draft, draft/doublings and drafts at speed frame, ring frame, rotor and air-jet spinning machine on packing density parameters of respective technology yarn was analysed. The effect of noise variables was also accounted for. The trends of change in packing density with process variables are opposite to those of yarn diameter and helix angle of ring, rotor and air-jet yarns studied. The packing density is found to be the highest in air-jet yarn and the lowest in rotor yarn. Increase in draft in air-jet spinner and decrease in rotor spinner increase packing density of the respective yarns. The change in noise variables does affect the packing density parameters of yarns. Result analysis using Taguchi Method was according to the perception of some of the previous researcher on the subject. Hence, Taguchi method can be also used to optimise a textile process, where the product quality is highly variable and dependent on the combination of number of processes as well as on machine parameters.
\end{abstract}

Keywords: ANOVA, controllable factors, noise variables, orthogonal array, packing density, regression model, spinning process, Taguchi method, yarn diameter.

\section{INTRODUCTION}

The application of Design of Experiment technique on the optimisation of an industrial process is being frequently used. These designs are considered as extremely useful tools in the modern industry. Infact, experimental designs have been used in the chemical industry for a long time and are now being increasingly used in other industries too. Several textile problems have also been studied by means of these techniques, though some of them are rather restricted in scope. Moreover, the optimisation of textile processes is quite cumbersome because it is affected by a number of factors which may or may not be controllable. There are various ways to optimise the effect of controllable variables by using Designs of Experiments like Factorial, Central composite, Box - Behnken etc. The main draw back of all these techniques is their inability to take in to account the effect of uncontrollable factor, like environmental conditions, spindle to spindle variation etc. The replications used in these designs bring out the variability under similar experimental conditions and process parameters.

Taguchi Method [1,2] is a technique which defines the quality as "The losses a product imparts to the society from the time it is supplied". This technique includes loss function associated with a product or process, robust design and simplified statistical experiments using orthogonal arrays. Taguchi Methodology states that even the best available manufacturing technology by itself is not an assurance to product quality. However, the final product will actually, function in the hands of its users as desired and so strongly advocated for the engineered products with robust performance. Taguchi described that quality should be measured by devia

*Address correspondence to this author at the The Abhishek Industries Ltd, Trident Complex, Barnala, Punjab, India, Tel: +919878998521, Pin 148101, E-mail: akshay_sardana@yahoo.com tion from a special target value, rather than by conformance to preset tolerance limits and quality cannot be ensured through inspection and rework, but must be built in through appropriate design of the process and product, which emphasized on the attainment of the specified target value and the elimination of variation $[3,4]$. Taguchi believes that the customer becomes increasingly dissatisfied in a quadratic manner as the performance departs farther away from the target, which accounts to the loss to quality [5,6]. Taguchi developed a Method that can take into account the effect of uncontrollable variables like humidity, machine conditions, etc. Taguchi method separately calculate the individual or main effects of the independent variables on performance parameters, while other designs give collective effect of variables in term of equations or 3D curves or contour diagrams. These equation or curves are sometimes not very easy to understand or interpret. Unlike other designs of experimental techniques, Taguchi method can only quantify the effect of subjective variables like whether yarn is produced on a new machine or the old one. In Taguchi method, variables are ranked according to the magnitude of their effect on the response variable. It establishes a composite measure called signal-to-noise ratio i.e. ratio of mean performance to variation in mean performance due to uncontrollable factors. The optimisation process by Taguchi Method can be done in minimum number of experimental runs. However, it may not always determine the interaction effect like other designs of experimental techniques. Considering the simplicity of the method and lower number of experimental runs required to optimise the process, Taguchi method can be a useful technique for optimizing textile processes [8-13].

Thus, the paper deals with the analysis of the effect of some spinning process variables on packing density of ring, rotor, air-jet yarns using Taguchi method; an outline for studying every stage of spinning process to get best possible 
information in minimum number of runs was prepared. Two levels of lap hank, four levels of card draft and two sets of draft/doublings at breaker and finisher draw frame were selected as control factors. The drafts at subsequent machines were chosen to prepare a common count on ring, rotor, and air-jet spinning machines. The choice of various factors level was based on the established process parameters normally used in the spinning industry.

The ANOVA technique was also used to quantify the contribution of each process variable in changing the response and for comparison with the ranking done by Taguchi method. Further, multiple regressions were fitted to the packing density parameters of all four yarns to figure out the effect of speed frame, ring frame, rotor, and air-jet spinning machine draft. Finally, the variability introduced by uncontrollable variables is also accounted for. The noise variables chosen for the present research are spindle to spindle variation, doff position, and material conditioning. The effect of noise variable factors is figured out for the different combination level of controllable factor for best response.

\section{MATERIALS AND METHODS}

\subsection{Preparation of Yarn Samples}

Viscose rayon staple fibre (44 mm, 1.67 dtex) was processed on spinning sequence of machines like: $\mathrm{L} \mathrm{R}$ blow room line \& Texmaco Howa card and given two passages on $\mathrm{L} R$ DO/6 draw frame (breaker and finisher). The samples were prepared according to $\mathrm{L}_{8}$ mixed orthogonal array [14,15], as shown in the Table 1. The factor levels at various stages were as chosen per some practical consideration. The prepared finisher sliver samples of eight different linear densities were processed into two different types of rovings and $24^{\mathrm{s}} \mathrm{Ne}$ rotor and air-jet yarns. For roving-type I, the draft at speed frame was kept constant in all the samples, while for roving-type II, the draft at speed frame was changed in such a way so as to produce same roving hank for all the eight samples. These rovings were processed two types of ring yarns, type I and II, in such a way so as to produce $24^{\mathrm{s}} \mathrm{Ne}$ yarns. The effect of uncontrollable variables such as, doff position, spindle to spindle variation, and material conditioning was duly taken in to consideration. $\mathrm{L}_{4}$ orthogonal array $[14,15]$ was considered for these variables during experimental run.

\subsection{Measurement of Packing Density in the Yarns}

In this regard, Ishtiaque [16] derived a formula to calculate the packing density of yarn. This formula is based on the actual values of yarn diameter, helix twist, and number of fibres in the yarn cross-section. The parameters needed for calculation of packing density like helix angle, helix twist, and yarn diameters were measured by using the classical tracer fibre technique [17]. Tracer fibres of red and green colour, each $0.03 \%$ by weight, were mixed with parent grey viscose fibres during fibre to yarn spinning. The configuration of tracer fibre was studied at 100 magnification, under projection microscope. Benzyl alcohol was used to optically dissolve the grey fibres in the yarn. Four different replications for packing density parameters at different noise factors level were taken, to take into account the effect of uncontrollable factors (noises). The packing density in the yarns was further calculated from the values of these parameters using the formula given below. The schematic view of a tracer fibre and a photograph of three different type of yarns, as seen under projection microscope for the study of yarn structure, are given in Fig. (1a) and (1b).

where, $\mathrm{D}=2 \mathrm{R}=$ yarn diameter (in $\mathrm{mm}$ ), $\mathrm{d}=2 \mathrm{r}=$ helix diameter (in $\mathrm{mm}), \theta=$ helix angle (in degrees) $=\tan ^{-1}(\pi \mathrm{d} \mathrm{Z} /$ 25.4), $\mathrm{Z}=$ number of turns of twist in fibre helix per $\mathrm{mm}$, and $\mathrm{n}=$ actual number of fibres in the yarn cross-section obtained by multiplying theoretical number of fibres in $24^{\mathrm{s}}$ $\mathrm{Ne}$ yarn by cosine of helix angle $(\theta)$. The theoretical number of fibres in yarn cross section $=148$ i.e. calculated by $\{5315 /$ (yarn count $(\mathrm{Ne}) \mathrm{x}$ fibre denier) $\}. \mathrm{F}^{\prime}$ is the cross sectional area of viscose fibre used $\left(\mathrm{mm}^{2}\right)=1.0964 \times 10^{-4}$;

Table 1. Sample Preparation Plan

\begin{tabular}{|c|c|c|c|c|c|c|c|c|c|c|c|c|c|c|}
\hline \multirow{5}{*}{ Run } & \multicolumn{3}{|c|}{ Design Variable Array } & \multirow{5}{*}{$\mid \begin{array}{c}\text { S/ F Draft } \\
\text { Type I }\end{array}$} & \multirow{5}{*}{$\begin{array}{l}\text { S/ F Draf } \\
\text { Type II }\end{array}$} & \multirow{5}{*}{$\begin{array}{c}\text { R/ F Draft } \\
\text { Type I }\end{array}$} & \multirow{5}{*}{$\begin{array}{c}\text { R/ F Draft } \\
\text { Type II }\end{array}$} & \multirow{5}{*}{$\begin{array}{l}\text { Rotor } \\
\text { Draft }\end{array}$} & \multirow{5}{*}{$\begin{array}{c}\text { Air-Jet } \\
\text { Draft }\end{array}$} & \multirow{2}{*}{\multicolumn{5}{|c|}{$\begin{array}{c}\text { Experimental Result Matrix } \\
\text { Noise Variable Array }\end{array}$}} \\
\hline & \multirow{4}{*}{$\begin{array}{l}\text { Lap Hank } \\
\text { (Ne) }\end{array}$} & \multirow{4}{*}{$\begin{array}{l}\text { Card } \\
\text { Draft }\end{array}$} & \multirow{4}{*}{$\begin{array}{l}\text { Draft/ Doublings } \\
\text { at Drawframe } \\
\text { (Breaker and Fin- } \\
\text { isher) }\end{array}$} & & & & & & & & & & & \\
\hline & & & & & & & & & & $\mathbf{A}$ & 1 & 2 & 2 & 1 \\
\hline & & & & & & & & & & B & 1 & 2 & 1 & 2 \\
\hline & & & & & & & & & & C & 1 & 1 & 2 & 2 \\
\hline 3 & 0.00122 & 101 & $6 / 6$ & 8.4 & 10.0 & 23.3 & 19.7 & 196.4 & 196.4 & & & R32 & R33 & R43 \\
\hline 4 & 0.00144 & 101 & $8 / 8$ & 8.4 & 8.4 & 19.7 & 19.7 & 166.4 & 166.4 & & & R42 & $\mathrm{R} 43$ & R44 \\
\hline 5 & 0.00122 & 114 & $8 / 8$ & 8.4 & 8.8 & 20.6 & 19.7 & 174.0 & 174.0 & & & R52 & R53 & R53 \\
\hline 6 & 0.00144 & 114 & $6 / 6$ & 8.4 & 7.5 & 17.5 & 19.7 & 147.4 & 147.4 & & & R62 & R63 & R63 \\
\hline
\end{tabular}

Where $\mathrm{S} / \mathrm{F}=$ speed frame, $\mathrm{R} / \mathrm{F}=$ ring frame, and in Noise variable array $\mathrm{A}=\operatorname{doff}$ position $(1=$ top , $2=$ bottom), $\mathrm{B}=$ spindle position( $1=$ spindle no $1 \& 2$ and $2=$ spindle no $3 \& 4$ ), and $\mathrm{C}=$ material conditioning in testing laboratory; 1 = unconditioned; 2 = conditioned. 


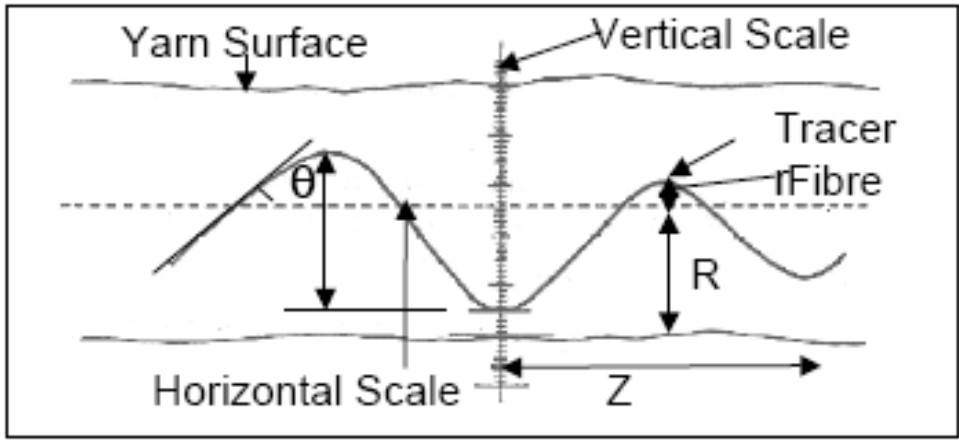

Fig. (1a). Schematic view of a tracer fibre seen under projection microscope.

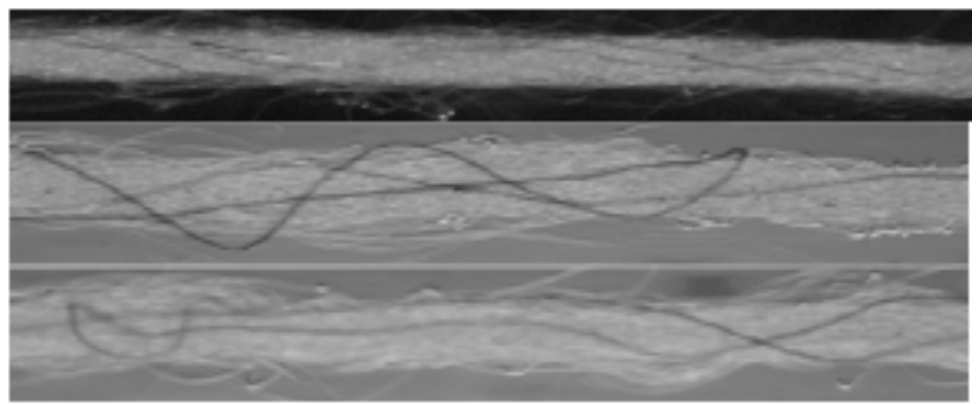

Fig. (1b). Photograph of a tracer fibre seen under projection microscope in ring (top), rotor and air-jet yarn (bottom.

Finally, the formula used for calculation of packing density from the above defined parameters is as follows:

Packing density of yarn $\left.=\mu=2 \pi n F Z^{2} /(\sqrt{1+(\pi D Z})^{2}-1\right)$

A total of 100 tracer fibres per sample (25 tracer fibres per replication) were studied for calculation of packing density parameters in all four yarns.

\subsection{Analysis of the Response}

Analysis of response depends upon whether smaller or larger value of the response is desired. The helix angle and yarn diameter were classified under the response type "smaller is better", because smaller the values of these parameters higher will be the packing density of the yarn. The helix twist was classified under the response type "larger is better", because higher values of this parameter is required to get higher packing density of the yarn. The packing density itself was classified under the response type "larger is better", because a higher value of packing density contributes positively towards yarn tenacity. The formulae used for the calculation of the $\mathrm{S} / \mathrm{N}$ ratio for the above response types are given below.

1. For "smaller is better"

$$
S / N=-10 \cdot \log _{10} \cdot\left(1 / n \sum_{i=1}^{n} y_{i}^{2}\right)
$$

Where $y_{i}=i^{\text {th }}$ value of the result and $n=$ number of replications;

2. For "larger is better"

$$
S / N=-10 . \log _{10} .\left(1 / n \sum_{i=1}^{n} 1 / y_{i}^{2}\right) \text {; }
$$

The actual values of $\mathrm{S} / \mathrm{N}$ ratio maximum were also evaluated directly from the curves of $\mathrm{S} / \mathrm{N}$ ratio with the change in process variable by using the equation:

$$
\begin{aligned}
& \overline{S / N} \max =\overline{S / N}+(S / N A \max -\overline{S / N}) \\
& +(S / N B \max -\overline{S / N})+(S / N C \max -\overline{S / N})
\end{aligned}
$$

where, $\overline{S / N} \max =$ maximum actual value from the graph

$\overline{S / N}=$ overall average value of the $\mathrm{S} / \mathrm{N}$ ratio

$S / N A \max =$ maximum value of $\mathrm{S} / \mathrm{N}$ ratio in plot of lap hank

$S / N B$ max $=$ maximum value of $\mathrm{S} / \mathrm{N}$ ratio in plot of card draft

$S / N C \max =$ maximum value of $\mathrm{S} / \mathrm{N}$ ratio in plot of draft/doublings

The calculated value is statistically compared with the actual value of $\mathrm{S} / \mathrm{N}$ ratio at $95 \%$ confidence level for significant difference between the two values. Like previous researchers [18], the rule followed was that if there is a significant difference in the two values, the experiment needs should be repeated by keeping the process variables at the optimum level observed from the graphs. Note that $\mathrm{S} / \mathrm{N}$ ratios of the various parameters should be maximized to get optimum set of process variables i.e for reading the plot, highest values of $\mathrm{S} / \mathrm{N}$ ratio are looked up for determining the optimum value of process variables in all the cases.

Further, the prepared $24^{\mathrm{s}} \mathrm{Ne}$ ring, rotor and air-jet yarn samples, as mentioned in above, were reconsidered for analysing the strength of noise variables, for study the effect of noise variables for best controllable factors combination for each response of packing density parameters. The noise vari- 
able array was reproduced by using the response row of the highest $\mathrm{S} / \mathrm{N}$ ratio. Then the effect for noise variables, such as spindle to spindle variation, doff position and material conditioning before testing is evaluated using simple analysis of $\mathrm{L}_{4}$ orthogonal array [1]. Further, the effect analysis can be understood by an example given below.

The effect of the different variables (A, B and C), as given in Table $\mathbf{2}$, on response (each packing density parameter) can be analysed by simple effect analysis such as;

Effect of $\mathrm{A}=$ (average result for $\mathrm{A}$ at setting 2) - (average result for $A$ at setting 1)

Effect of B = (average result for B at setting 2) - (average result for $\mathrm{B}$ at setting 1 )

Effect of $\mathrm{C}=$ (average result for $\mathrm{C}$ at setting 2) - (average result for $\mathrm{C}$ at setting 1 )

Table 2. $\quad \mathrm{L}_{4}$ Orthogonal Array

\begin{tabular}{|c|c|c|c|c|}
\hline Run & A & B & C & Response \\
\hline \hline 1 & 1 & 1 & 1 & R1 \\
\hline 2 & 2 & 2 & 1 & R2 \\
\hline 3 & 2 & 1 & 2 & R3 \\
\hline 4 & 1 & 2 & 2 & R4 \\
\hline
\end{tabular}

In the present research work the different noise variables were: 'A' = doff position ( $1=$ top, $2=$ bottom $),{ }^{B}$ ' = spindle position $(1=$ spindle nos. 1 and $2,2=$ spindle nos. 3 and 4 i.e. the spindle group driven with same spindle tape in ring yarn, whereas, in rotor and air-jet yarn spindle position refers to two different winding drum position), and ' $\mathrm{C}$ ' = material conditioning in testing laboratory $(1=$ unconditioned; $2=$ conditioned at $65 \%$ R.H. and $25^{\circ} \mathrm{C}$ for $8 \mathrm{hrs}$ ).
The ring yarns (- type I and - type II) were tested at two different position of ring cop i.e. at the beginning of cop filling (bottom) and at the final position (top, filled cop), where as rotor and air-jet yarn cheeses were tested at beginning (bottom) and at $20000 \mathrm{~m}$ length (marked as top). Further, the two bobbins, each of the two spindles running with same tape, were taken from two different positions and marked as position 1 and 2. Furthermore, samples were tested for the effect of laboratory conditioning at standard humidity and temperature for specified time. So, for the best controllable combination of factors level (at highest $\mathrm{S} / \mathrm{N}$ ratio), $\mathrm{L}_{4}$ noise variable array was reproduced and the effect of noise factors was analysed.

\section{RESULTS AND DISCUSSION}

Tables 3 to 6 show the $\mathrm{S} / \mathrm{N}$ ratios and mean values of parameters required for calculating packing density in ring, rotor and air-jet yarns in eight different samples prepared. The overall percentage changes by process variables and actual values of $\mathrm{S} / \mathrm{N}$ ratios with $95 \%$ confidence limits ( $\mathrm{S} / \mathrm{N}$ $\mathrm{L}$ and $\mathrm{S} / \mathrm{N} \mathrm{H}$ ) of various packing density parameters studied are also given in the respective tables. The average values of $\mathrm{S} / \mathrm{N}$ ratios and mean values are given in the last row of respective tables. Since, the highest calculated values of S/N ratio are lying within $95 \%$ confidence limits for actual response by graphical method therefore in all the cases there was no need to do a confirmatory test.

\subsection{Effect of Process Variables on Helix Angle}

Table 3 shows that the average helix angle in ring yarntype I is more than the air-jet yarn, but less than the rotor yarn. This is because, as shown in Fig. (1b), ring yarn fibres are well oriented due to better drafting and fibre control in ring frame, which gives better parallelisation of fibres inside

Table 3. S/N Ratios (Smaller is Better) and Mean Values of Helix Angle in Various Yarn

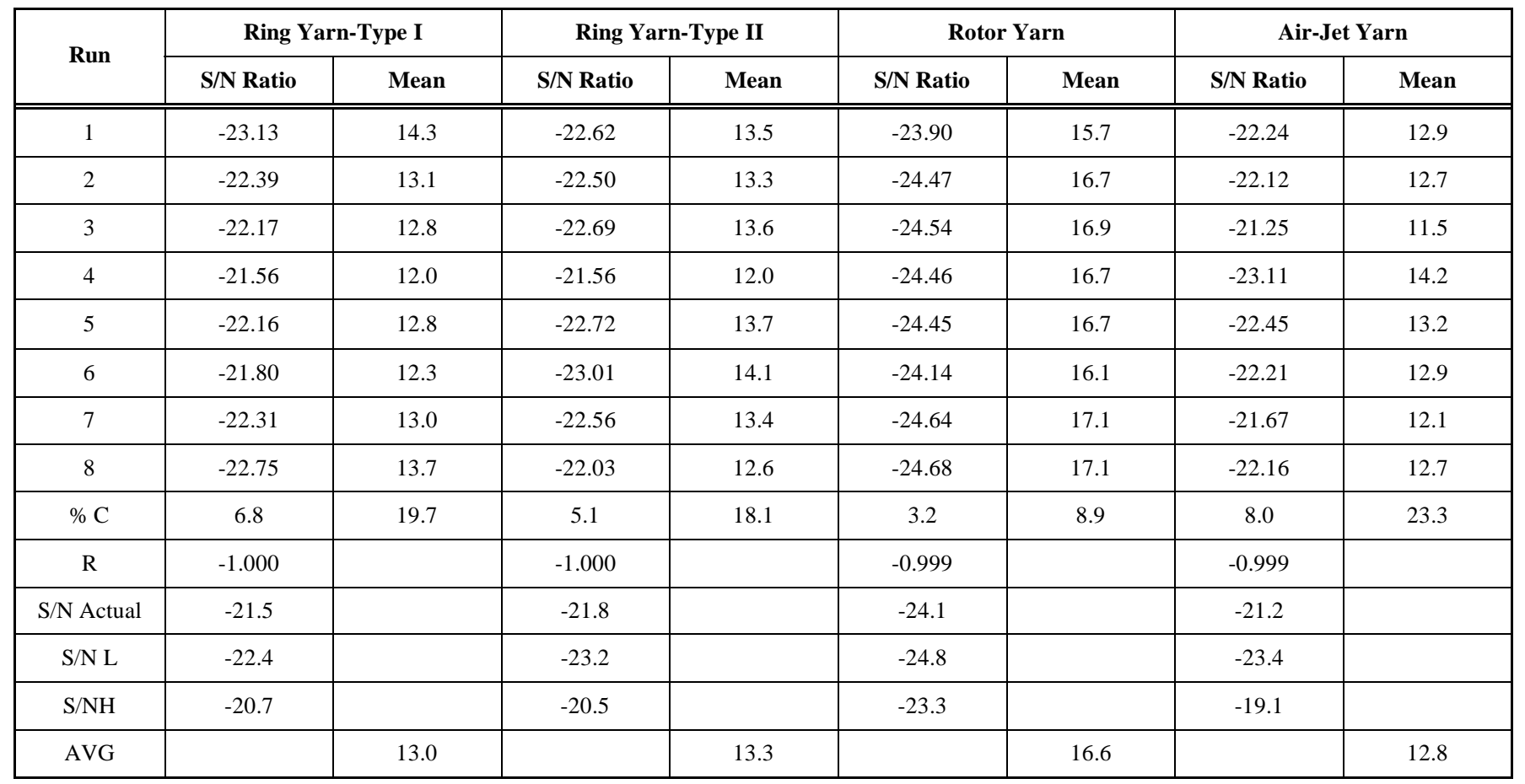


Table 4. S/N Ratios (Larger is Better) and Mean Values of Number of Turns of Twist in Fibre Helix (per inch) in Yarns

\begin{tabular}{|c|c|c|c|c|c|c|c|c|}
\hline \multirow{2}{*}{ Run } & \multicolumn{2}{|c|}{ Ring Yarn-Type I } & \multicolumn{2}{|c|}{ Ring Yarn-Type II } & \multicolumn{2}{|c|}{ Rotor Yarn } & \multicolumn{2}{|c|}{ Air-Jet Yarn } \\
\hline & S/N Ratio & Mean & S/N Ratio & Mean & S/N Ratio & Mean & S/N Ratio & Mean \\
\hline 1 & 23.68 & 15.30 & 23.27 & 14.66 & 25.62 & 19.15 & 25.01 & 17.82 \\
\hline 2 & 23.24 & 14.56 & 23.27 & 14.60 & 25.84 & 19.69 & 23.37 & 14.86 \\
\hline 3 & 23.05 & 14.21 & 23.53 & 15.04 & 25.70 & 19.31 & 23.24 & 14.60 \\
\hline 5 & 23.75 & 15.42 & 23.64 & 15.23 & 25.71 & 19.32 & 24.27 & 16.40 \\
\hline 6 & 23.55 & 15.10 & 23.68 & 15.40 & 25.57 & 19.11 & 23.76 & 15.54 \\
\hline 7 & 23.56 & 15.17 & 23.29 & 14.62 & 25.66 & 19.30 & 24.00 & 15.87 \\
\hline 8 & 23.54 & 15.11 & 22.92 & 14.00 & 25.65 & 19.31 & 23.91 & 16.26 \\
\hline $\mathrm{S} / \mathrm{N} \mathrm{L}$ & 23.1 & & 23.2 & & 25.3 & & 21.3 & \\
\hline $\mathrm{S} / \mathrm{NH}$ & 24.4 & & 24.3 & & 26.3 & & 27.4 & \\
\hline AVG & & 14.9 & & 14.7 & & 19.2 & & 16.0 \\
\hline
\end{tabular}

the yarn body. In air-jet yarn, wrappers have an end which lies almost straight in the core. Further, fibres in the core are almost straight, giving rise to lower helix angle. In rotor yarn, the higher mechanical twist required for yarn manufacturing and random arrangement of fibres (hooks, loops and buckling) and yarn twist mechanism necessitate more twist, due to more torque required to twist the consolidated fibre band in rotor groove which gives higher value of helix angle.
Table 7 shows the effect of changes in spinning process variables on helix angle in ring yarns. The change in card draft and corresponding changes in ring frame draft followed by draft/doublings and lap hank influence most of the change in helix angle. A high value of $\mathrm{R}^{2}$ shows that helix angle is considerably influenced by the changes in preparatory process variables. Further, there is considerable effect of change in ring frame draft on helix angle. In ring yarn-type II, the change in card draft is the major influencing factor followed

Table 5. S/N Ratios (Smaller is Better) and Mean Values (1/100 mm) of Yarn Diameter

\begin{tabular}{|c|c|c|c|c|c|c|c|c|}
\hline Run & \multicolumn{2}{|c|}{ Ring Yarn-Type I } & \multicolumn{2}{|c|}{ Ring Yarn-Type II } & \multicolumn{2}{|c|}{ Rotor Yarn } & \multicolumn{2}{|c|}{ Air-Jet Yarn } \\
\hline 1 & -26.1 & 20.2 & -26.6 & 21.5 & -27.3 & 23.2 & -25.8 & 19.4 \\
\hline 2 & -25.8 & 19.6 & -26.5 & 21.0 & -27.5 & 23.7 & -25.6 & 19.1 \\
\hline 3 & -26.3 & 20.6 & -26.5 & 21.2 & -27.4 & 23.5 & -25.8 & 19.4 \\
\hline 6 & -26.0 & 20.0 & -26.3 & 20.7 & -26.8 & 21.8 & -26.2 & 20.4 \\
\hline 7 & -26.3 & 20.8 & -26.3 & 20.6 & -26.9 & 22.2 & -26.1 & 20.1 \\
\hline 8 & -26.3 & 20.7 & -26.4 & 20.8 & -27.3 & 23.2 & -26.1 & 20.0 \\
\hline$\% \mathrm{C}$ & 1.74 & 5.40 & 3.29 & 10.50 & 2.56 & 8.49 & 2.18 & 6.67 \\
\hline $\mathrm{S} / \mathrm{N} \mathrm{L}$ & -26.03 & & -26.50 & & -28.24 & & -26.21 & \\
\hline $\mathrm{S} / \mathrm{NH}$ & -25.44 & & -25.32 & & -25.88 & & -25.08 & \\
\hline AVG & & 20.12 & & 20.68 & & 23.01 & & 19.82 \\
\hline
\end{tabular}


Table 6. S/N Ratios (Larger is Better) and Mean Values of Packing Density of Yarns

\begin{tabular}{|c|c|c|c|c|c|c|c|c|}
\hline \multirow{2}{*}{ Run } & \multicolumn{2}{|c|}{ Ring Yarn-Type I } & \multicolumn{2}{|c|}{ Ring Yarn-Type II } & \multicolumn{2}{|c|}{ Rotor Yarn } & \multicolumn{2}{|c|}{ Air-Jet Yarn } \\
\hline & S/N Ratio & Mean & S/N Ratio & Mean & S/N Ratio & Mean & S/N Ratio & Mean \\
\hline 1 & -5.96 & 0.506 & -6.97 & 0.454 & -8.07 & 0.396 & -5.11 & 0.557 \\
\hline 2 & -5.36 & 0.541 & -6.56 & 0.470 & -8.44 & 0.380 & -4.97 & 0.566 \\
\hline 3 & -6.20 & 0.491 & -6.74 & 0.466 & -8.30 & 0.385 & -5.17 & 0.557 \\
\hline 5 & -5.27 & 0.547 & -5.99 & 0.503 & -8.36 & 0.384 & -5.60 & 0.530 \\
\hline 6 & -5.72 & 0.520 & -6.26 & 0.486 & -7.13 & 0.443 & -6.10 & 0.504 \\
\hline 7 & -6.35 & 0.485 & -6.25 & 0.492 & -7.39 & 0.428 & -5.74 & 0.521 \\
\hline 8 & -6.34 & 0.483 & -6.38 & 0.482 & -8.30 & 0.396 & -5.77 & 0.525 \\
\hline $\mathrm{S} / \mathrm{N} \mathrm{L}$ & -5.69 & & -6.65 & & -9.99 & & -5.90 & \\
\hline $\mathrm{S} / \mathrm{NH}$ & -4.55 & & -4.31 & & -5.33 & & -3.91 & \\
\hline AVG & & 0.515 & & 0.488 & & 0.401 & & 0.534 \\
\hline
\end{tabular}

by lap hank. The draft/doublings have negligible effect. A high value of $\mathrm{R}^{2}$ shows that helix angle is greatly influenced by changes in preparatory process variables. The effect of change in speed frame draft on the helix angle is only marginal.

Table $\mathbf{8}$ shows, in rotor yarn, the card draft is the major influencing factor followed by draft/doublings and lap hank.
A high value of $\mathrm{R}^{2}$ shows that helix angle is greatly influenced by changes in preparatory process variables. The effect of change in rotor draft on helix angle is negligible. In air-jet yarn, the change in lap hank is major, influencing factor followed by the change in draft/doublings followed by the change in card draft. The value of $\mathrm{R}^{2}$ shows that helix angle is greatly influenced by changes in preparatory process

Table 7. Effect of Process Variables on Change in S/N Ratios of Helix Angle, Helix Twist, Yarn Diameter and Packing Density in Ring Yarn as Analysed by Taguchi Method and ANOVA Technique

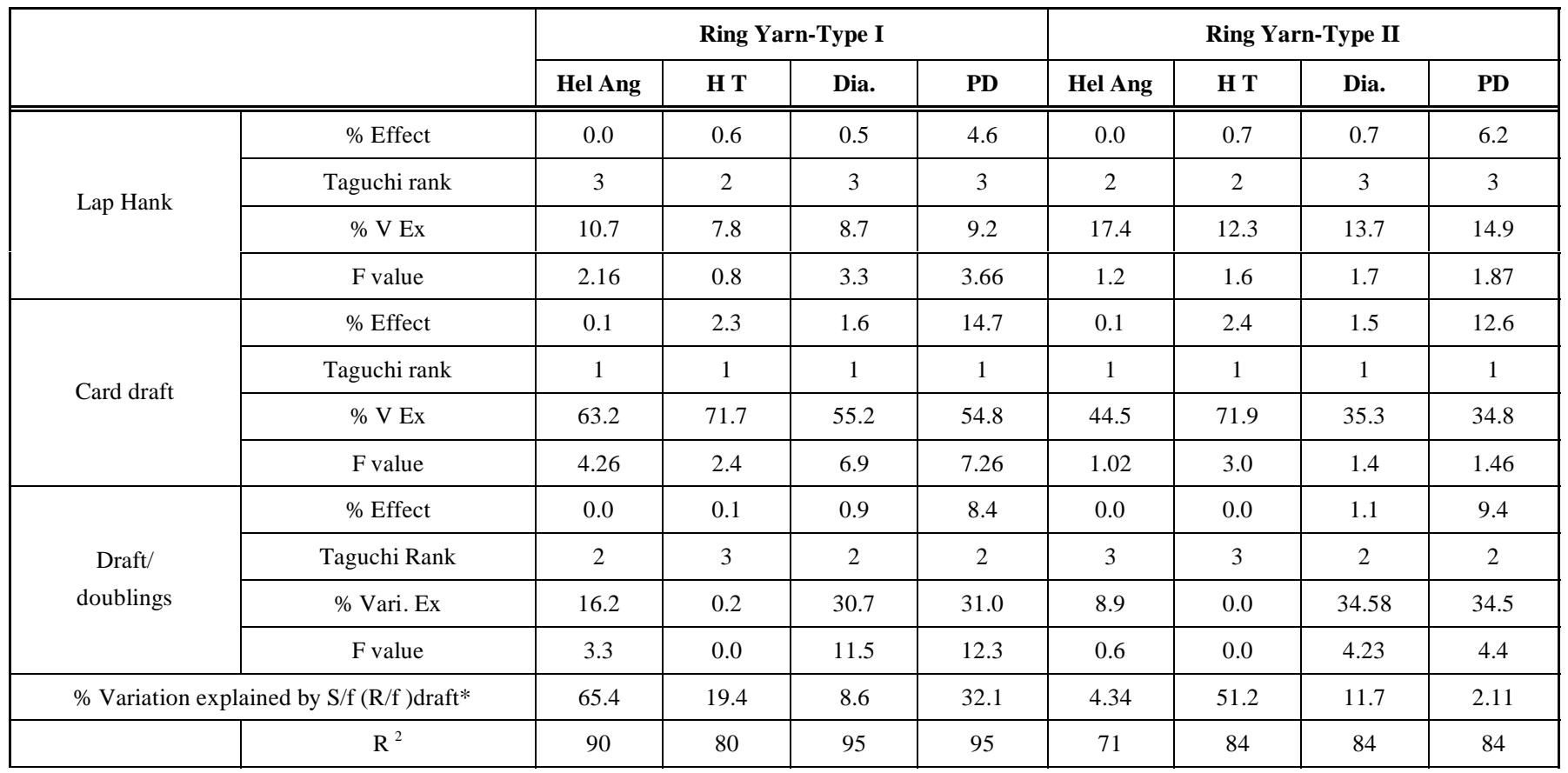

Where, Hel ang $=$ helix angle, H.T. $=$ helix twist, Dia $=$ yarn diameter $\mathrm{PD}=$ packing density,$\% \mathrm{~V} \mathrm{Ex}=\%$ variation explained. 
Table 8. Effect of Process Variables on Change in S/N Ratios of Helix Angle, Helix Twist, and Packing Density in Rotor and AirJet Yarn as Analysed by Taguchi Method and ANOVA Technique

\begin{tabular}{|c|c|c|c|c|c|c|c|c|c|}
\hline & & \multicolumn{4}{|c|}{ Rotor Yarn } & \multicolumn{4}{|c|}{ Air-jet yarn } \\
\hline & & Hel Ang & H. T & Dia. & PD & Hel Ang & H.T. & Dia. & PD \\
\hline \multirow{4}{*}{ Lap Hank } & $\%$ Effect & 0.0 & 0.2 & 0.2 & 0.8 & 0.1 & 1.0 & 0.5 & 4.9 \\
\hline & Taguchi rank & 3 & 2 & 2 & 3 & 1 & 2 & 2 & 2 \\
\hline & $\% \mathrm{~V} \mathrm{Ex}$ & 1.2 & 4.9 & 1.4 & 0.6 & 23.95 & 4.8 & 9.7 & 13.0 \\
\hline & F value & 0.08 & 0.15 & 0.0 & 0.01 & 0.88 & 0.10 & 0.8 & 1.29 \\
\hline \multirow{4}{*}{ Card draft } & $\%$ Effect & 0.1 & 0.6 & 1.1 & 6.4 & 0.0 & 1.3 & 1.5 & 14.5 \\
\hline & Taguchi rank & 1 & 1 & 1 & 1 & 2 & 1 & 1 & 1 \\
\hline & $\%$ V Ex & 57.9 & 28.5 & 25.7 & 21.3 & 8.62 & 4.3 & 64.5 & 66.8 \\
\hline & F value & 1.4 & 0.29 & 0.2 & 0.18 & 0.11 & 0.03 & 1.7 & 2.21 \\
\hline \multirow{4}{*}{$\begin{array}{c}\text { Draft/ } \\
\text { doublings }\end{array}$} & $\%$ Effect & 0.0 & 0.10 & 0.2 & 1.1 & 0.0 & 0.24 & 0.0 & 0.2 \\
\hline & Taguchi rank & 2 & 3 & 3 & 2 & 3 & 3 & 3 & 3 \\
\hline & $\%$ V Ex & 13.3 & 1.45 & 1.4 & 1.0 & 13.3 & 0.25 & 0.0 & .02 \\
\hline & F value & 1.0 & 0.04 & 0.0 & 0.0 & 0.49 & 0.01 & 0.0 & 0 \\
\hline \multicolumn{2}{|c|}{$\%$ Variation explained by rotor(A/J )draft* } & 1 & 4.3 & 2.3 & 2.7 & $(0.4)$ & $(16.7)$ & $(5.7)$ & (7.7) \\
\hline & $\mathrm{R}^{2}$ & 72 & 35 & 28 & 23 & 46 & 9 & 74 & 80 \\
\hline
\end{tabular}

Where, Hel ang = helix angle, $\mathrm{H} . \mathrm{T}=$ helix twist, Dia. = yarn diameter, $\mathrm{PD}=$ packing density $\% \mathrm{~V} \mathrm{Ex}=\%$ variation explained.

variables. The effect of change in air-jet draft on helix angle is negligible.

Fig. (2) shows the $\mathrm{S} / \mathrm{N}$ ratio plots of helix angle with change in process variables in all four yarns. Increase in lap hank and corresponding decrease in ring frame draft decreases the helix angle. This is because finer lap hank and corresponding lower ring frame draft reduces the width of drafting band in the drafting zone of ring frame which further reduces the convergence angle of fibres in spinning triangle (comparatively shorter) during yarn formation zone, and thus is responsible for reduction in helix angle. Also, feeding of finer lap hank at card improves opening and carding action of fibres. These fibres show better tendency of straightening and parallelisation in the subsequent process of drafting, and thus reduce helix angle in resultant yarn even at lower ring frame draft [19]. The effect of card draft and corresponding change in ring frame draft counterbalance each other in deciding the helix angle. As the card draft increases from 88 to 101, the helix angle in yarn decreases because of increased fibre straightening in the subsequent drafting zone. Further, increase in card draft from 101 to 127 and corresponding decrease in ring frame draft increases the helix angle [7]. Increase in draft/ doublings at draw frame reduces

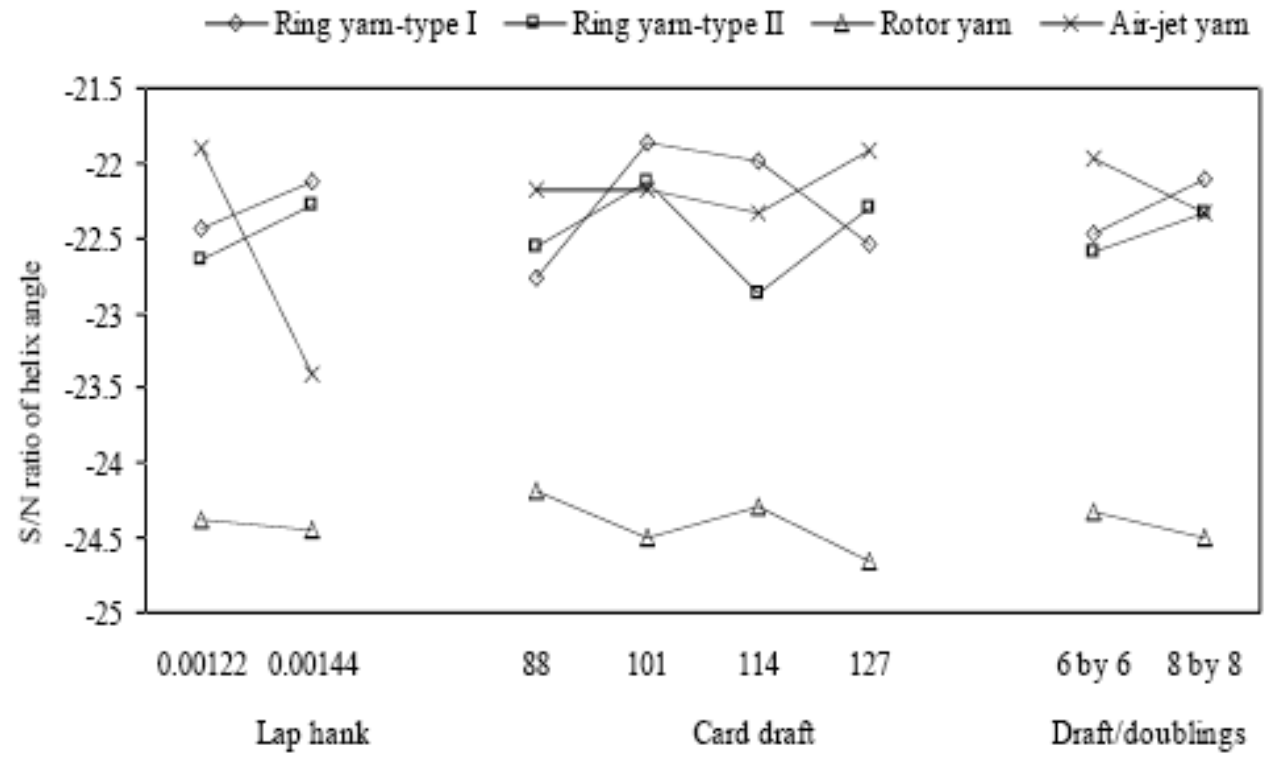

Fig. (2). S/N ratio plot of helix angle with change in process variables. 
the helix angle. This is because increase in draft/ doublings increases the compactness of sliver due to increase in the width of fibre band in drafting zone of draw frame, which increases the tension, in edge fibres of the delta zone. These edge fibres try to migrate inside the sliver body to ease its tension and thus produce compact sliver. This compact sliver produces compact roving which furthur produces smaller width of drafting band in ring frame drafting zone. Finally, it reduces the helix angle in the yarn. This relationship between the width of drafting ribbon and helix angle is in agreement with the findings of Ishtiaque et al. [20] and Ishtiaque et al. [21]. Further, like in ring yarn-type I, the increase in lap hank and draft/doublings decreases the helix angle in ring yarn-type II. The change in card draft changes the helix angle in a random way with no particular trend. Further, in rotor yarn, increase in lap hank, card draft and draft/doublings increases the helix angle in yarn. This is because of decrease in fibre parallelisation and straightening in the sliver and yarn [7]. In air-jet yarn, the increase in draft/doublings and lap hank \& corresponding decrease in air-jet draft increase the helix angle. This is because of reduction in width of fibre band with finer lap hank \& corresponding lower air-jet draft and higher draft/doublings (due to greater compactness), in drafting zone of air-jet machine. An increase in card draft marginally changes the helix angle. The helix angle slightly increases from 88 to 114 card draft and corresponding decrease in air-jet draft is due to decrease in ribbon width, as explained in the case of finer lap hank, and corresponding decrease in air-jet draft. Further, from 114 to 127 card draft the helix angle decreases in the yarn. This is because at 114 card draft and relatively higher air-jet draft the ribbon width is more than 127 card draft. So, at higher width more fibres are detached from the twisting core at front roller nip and they describe a longer curvature and big balloon to meet again in the twisting core by making higher angle with twisting axis. Thus, the delay in re-entering of detached fibres, which shifts the convergence point away from the front roller nip, is responsible for higher helix angle in yarn at 114 card draft.

The value of actual number of fibres is calculated by multiplying the theoretical number of fibres in the yarn cross section by the cosine of the helix angle. So, it reflects the same trends as helix angle in the different yarns.

\subsection{Effect of Process Variables on Helix Twist}

Table 3 shows that the average values of helix twist in the ring yarn-type I is lower than those of rotor and air-jet yarn. This is because ring yarn fibres are well oriented due to better drafting and fibre control in ring frame which gives better parallelisation of fibres inside the yarn body similar to the helical model. Thus, lower mechanical twist is required to produce ring yarn equivalent to rotor and air-jet yarn. However, the average helix twist in ring yarn-type II is slightly lower than in ring yarn-type I. Further, the average helix twist in rotor yarn is the highest amongst the three yarns. This is because in rotor yarn, a high mechanical twist and presence of high twist in the yarn core give rise to the highest value of helix twist. Further, the average helix twist in air-jet yarn is lower than the rotor yarn, but more than the ring yarn due to high twist frequency of wrapper fibres. But, one end of wrapper always lies straight in the yarn core (which is at lower helix twist). Also, core fibres are almost straight with negligible twist. These counterbalancing factors give rise to helix twist values, higher than ring yarn but lower than rotor yarn. In the air-jet yarn, the higher value of twist frequency leads to higher value of average helix twist.

Table 7 shows the effect of spinning process variables on helix twist in ring yarns. The change in card draft and corresponding changes in ring frame draft influences most of the changes in helix twist followed by that of lap hank. The effect of draft/doublings on helix twist is the least. A high value of $R^{2}$ shows that helix twist is considerably influenced by changes in preparatory process variables. The effect of change in ring frame draft on helix twist is considerable. In ring yarn-type II, the change in card draft and corresponding speed frame draft is seen to be the major influencing factor followed by lap hank and corresponding speed frame draft. The change in draft/doublings has no effect on helix twist. A high value of $\mathrm{R}^{2}$ shows that helix twist is considerably influenced by changes in process variables. The effect of change in speed frame draft on the helix twist is considerable.

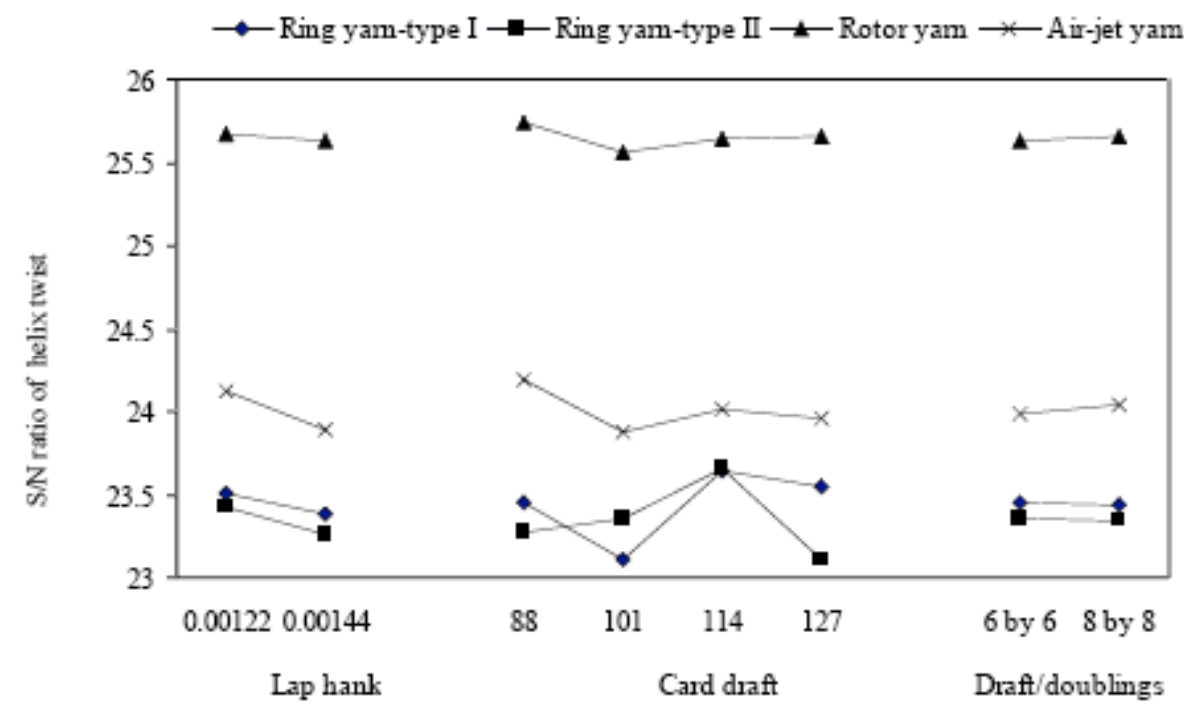

Fig. (3). $\mathrm{S} / \mathrm{N}$ ratio plot of helix twist with the change in process variables. 
Table 8 shows the effect of change in preparatory process variables on helix twist in rotor and air-jet yarn. The change in card draft is seen to be the major influencing factor. The effect of draft/doublings and lap hank is only marginal. A moderate value of $R^{2}$ shows that helix twist is influenced by changes in preparatory process variables. The effect of change in rotor draft on the helix twist is negligible. In air-jet yarn, a very low value of $\mathrm{R}^{2}$ in the table shows that the helix twist is not influenced by changes in process variables. However, the small changes in helix twist in air-jet yarn can be attributed to air-jet draft.

Fig. (3) shows the S/N ratio plots of helix twist with change in process variables in all four yarns. Increase in lap hank and corresponding decrease in ring frame draft decrease the helix twist in the yarn marginally. The effect of change in card draft and corresponding changes in ring frame draft on helix twist does not show any clear trend. The increase in draft/ doublings does not alter the helix twist. The increase in lap hank and corresponding decrease in the speed frame draft decrease the helix twist in the yarn. The change in helix twist with the change in card draft and corresponding change in speed frame draft passes through a maximum. The overall changes in helix twist are only marginal with the change in process variables in rotor and air-jet yarns. Increase in lap hank, card draft and draft/doublings does not affect the helix twist much.

\subsection{Effect of Process Variables on Yarn Diameter}

Table 5 shows that the average diameter of ring yarn-type I is higher than the diameter of air-jet yarn but lower than rotor yarn. The average diameter of ring yarn-type II is slightly higher than ring yarn- type I. This is because in rotor yarn the loosely bound wrapper fibres on the surface increase the diameter when compared with the equivalent ring and air-jet yarns. Also, rotor yarn fibres are deposited in the rotor groove in the form of triangular fibre band. But in twisting, at final yarn formation the corner of triangular band collapses and these fibres are loosely wrapped over the yarn surface. Fibres lying inside triangular band are firmly twisted and form solid yarn core. These could be the reasons of higher rotor yarn diameter. In air-jet yarn, parallel core fibres are bound by tight wrapper fibres which results in the least diameter.

Table 7 shows the effect of change in process variables on change in yarn diameter of ring yarns. The effect of card draft and corresponding ring frame draft and draft/doublings at draw frame influences most of the change in the yarn diameter. The effect of change in card draft is almost significant at $90 \%$ confidence level and effect of change in draft/doublings is significant at $90 \%$ confidence level. The effect of lap hank on change in yarn diameter is only marginal. A very high value of $\mathrm{R}^{2}$ shows that the process variables influence the yarn diameter considerably. However, the effect of change in ring frame draft influences the yarn diameter. In ring yarn-type II, the effect of card draft and corresponding speed frame draft and draft/doublings at draw frame explains most of the variations in yarn diameter. The effect of change in lap hank on yarn diameter is the least. A high value of $R^{2}$ shows that the process variables influence the yarn diameter considerably. The effect of change in speed frame draft influences the change in yarn diameter.
Table 8 shows the effect of change in process variables on change in yarn diameter of rotor and air-jet yarn. A lower value of $\mathrm{R}^{2}$ shows that the process variables do not affect the yarn diameter much. However, most of the change in diameter is due to change in card draft only. The changes in lap hank and draft/doublings have no effect on yarn diameter. The effect of change in rotor draft is only marginal. A high value of $\mathrm{R}^{2}$ shows that the process variables influence the air-jet yarn diameter. However, most of the change in diameter is due to the change in card draft and corresponding changes in air-jet draft only. The effect of change in lap hank is only marginal and draft/doublings have no effect on yarn diameter. The change in air-jet draft influences the yarn diameter.

Fig. (4) shows the $\mathrm{S} / \mathrm{N}$ ratio plot of yarn diameter with change in process variables in all four yarns. Finer lap hank and corresponding lower ring frame draft reduce the diameter of yarn. This is because of reduction in the width of fibre band in the drafting zone at lower ring frame draft, which produces a compact yarn with smaller yarn diameter. The increase in card draft (from 88 to 114 card draft) and corresponding decrease in ring frame draft tends to decrease the diameter of yarn marginally due to the reasons described above. Further, increase in card draft (from 114 to 127) and corresponding decrease in ring frame draft increases the diameter. This is because of the considerable reduction in ribbon width at front roller. So, the tension arising in the edge fibres in the spinning triangle reduces due to the reduction in path length of the fibres, which further reduces the fibre migration in yarn body, and thus lowers the compactness of the yarn [9]. The yarn so produced has greater diameter. Increase in draft/doublings decreases the yarn diameter due to the increase in compactness of the fibre band, as already explained. The dependence of yarn compactness on the ribbon width and subsequent fibre migration parameters is in accordance with the findings of Ishtiaque et al. [20]. Like in ring yarn-type I, the finer lap hank and higher draft/doublings reduce the yarn diameter in ring yarn type II. The increase in card draft (from 88 to 101) and corresponding decrease in speed frame draft reduces the yarn diameter. This could be due to reduction of draft at speed frame which reduces the ribbon width and makes yarn more compact. Further, though an increase in card draft and corresponding reduction in speed frame draft reduces the width of fibre band, it reduces the fibre migration in roving due to decrease in tension in edge fibres [7]. This makes the roving and corresponding yarn less compact having bigger diameter.

In rotor yarn, increase in card draft and corresponding decrease in rotor draft decrease the yarn diameter. This is because of the increase in fibre tension [7]. This helps the fibre to uniformly deposit in the rotor groove, and thus increases the compactness of fibre band in the rotor groove and produces the yarn with smaller diameter. Overall, the yarn diameter depends on the compactness of fibre band in the rotor groove, which in turn is mainly dependent on the centrifugal force, and thus, on the rotor speed. These factors are almost the same because rotor speed is the same. This could be the reason of less dependence of rotor yarn diameter on process variables chosen.

In air-jet yarn, finer lap hank and increase in card draft and corresponding decrease in air-jet draft increase the yarn 


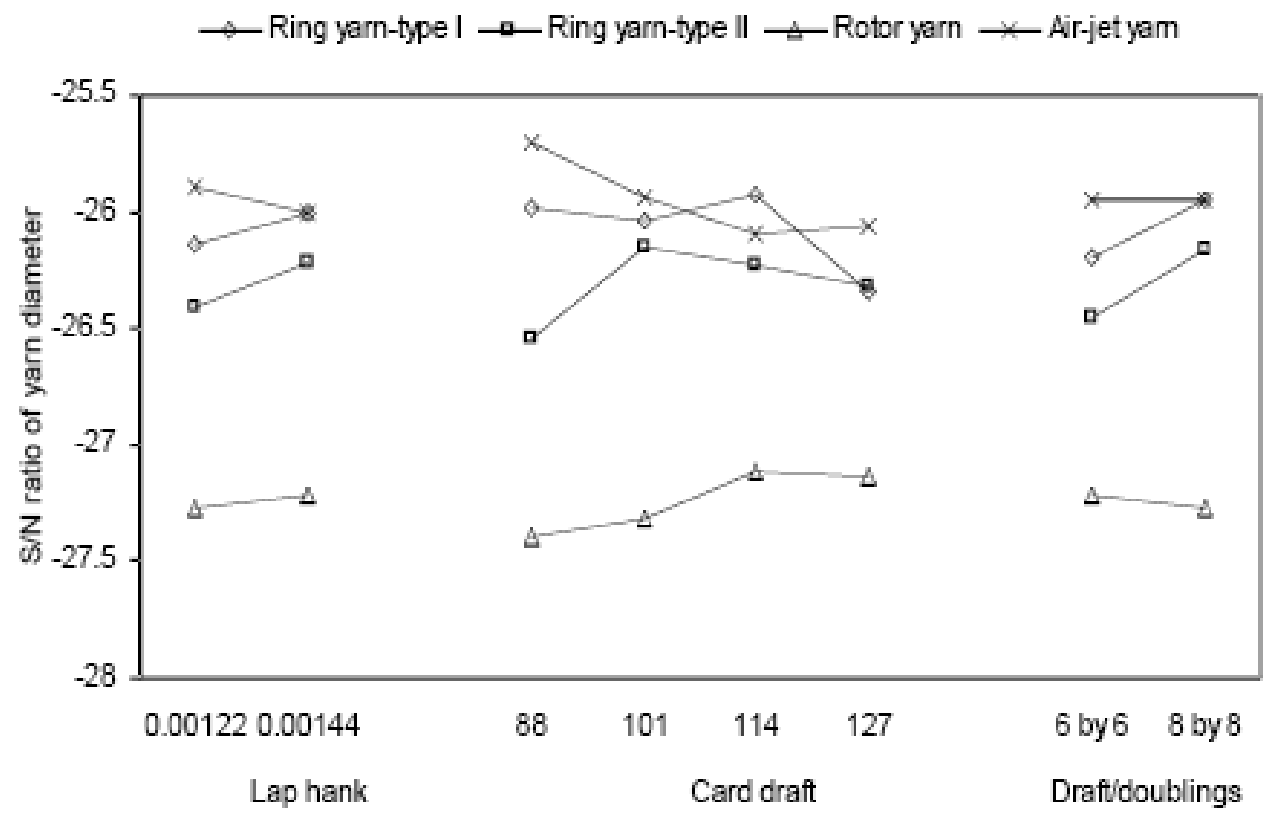

Fig. (4). S/N ratio plot of yarn diameter with change in process variables.

diameter. This is due to the decrease in width of fibre band, which reduces the wrapper twist frequency and generation of wrappers fibres $[21,22]$. This reduces the binding force generated by wrappers on the core of parallel fibres, and thus, produces yarn with lower compactness and bigger diameter. The draft/ doublings have no influence on yarn diameter.

\subsection{Effect of Process Variables on Packing Density}

Table 6 shows that the average packing density of ring yarn- type I is higher than the rotor yarn but lower than the air-jet yarn. This is because the ring yarn has greater yarn diameter than the equivalent air-jet yarn and smaller than the rotor yarn. Also, in ring yarn, fibres change from a thin ribbon to a roughly circular shape with fibres gripped at the nip of the front roller. The outermost fibres are under greater strain and unless there is excessive yarn tension, the core is subjected to compression. In one case, the stress is relieved by shortening the path length of fibre in yarn, and in the other case, by lengthening it. The net result is that fibres depart from a purely helical configuration to give an interlocking structure, which has higher packing density in comparison to rotor yarn [19]. However, the packing density of rotor yarn is the least amongst the three yarns. The rotor yarn, posseses a single helical structure and the fibres are distributed from inner core to the outer core without fibre migration. The fibres are twisted more uniformly as a result of which the inner core receives more compression. The inner zone is subjected to a variety of tensions in spinning and the migrated structure will be somewhat similar to that of ringspun yarn. Thus, the packing density of inner zone is higher in rotor yarn as compared to the packing density of inner core of ring yarn. But, intermediate and outer zones contain hairs and loosely bound wrapper fibres and have less packing density than ring yarn in these zones. Overall, packing density of rotor yarn is less than the ring yarn. Also, the higher rotor yarn diameter is responsible for least packing density [19].
Table 7 shows the effect of change in process variables on change in packing density of ring yarns. The effect of card draft and corresponding ring frame draft and draft/doublings at draw frame explains most of the change in packing density. The effect of change in card draft is almost significant at $90 \%$ confidence level and effect of change in draft/doublings is significant at $90 \%$ confidence level. The effect of change in lap hank on yarn packing density is the least. A very high value of $\mathrm{R}^{2}$ in the table shows that the change in process variables highly influencing the packing density. The effect of change in ring frame draft considerably influenced the change in packing density. In ring yarntype II, the effect of card draft and draft/doublings at draw frame explains most of the change in yarn packing density. The effect of change in lap hank on packing density is the least. A high value of $\mathrm{R}^{2}$ indicates that the process variables considerably influence the packing density. The effect of change in speed frame draft on packing density is marginal.

Table 7 shows the effect of change in process variables on change in yarn packing density of rotor and air-jet yarn. A low value of $\mathrm{R}^{2}$ shows that the process variables do not affect the yarn packing density much. However, most of the change that is being influenced by process variables can be attributed to card draft. The effect of change in lap hank and draft/doublings has no effect on packing density. The effect of change in rotor draft is only marginal. A high value of $\mathrm{R}^{2}$ shows that the process variables considerably influence the air-jet yarn packing density. The change in card draft and corresponding change in air-jet draft influence most of the change in packing density. The effect of change in lap hank follows the effect of card draft. The change in draft/doublings has no effect on packing density. The change in air-jet draft also influences the packing density.

Fig. (5) shows the S/N ratio plot of packing density of ring yarn with change in process variables in all four yarns. Finer lap hank and corresponding lower ring frame draft increase the packing density of yarn. This is because of the 


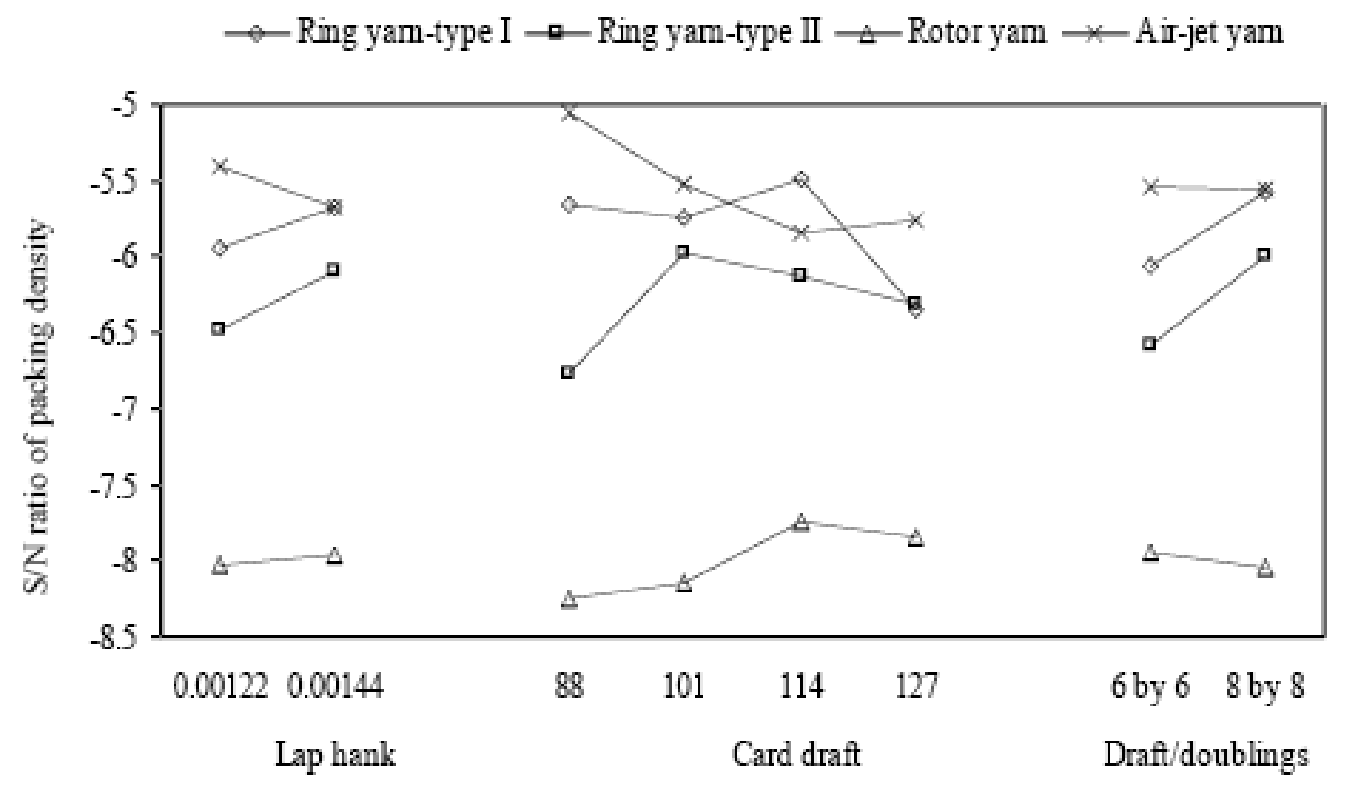

Fig. (5). S/N ratio plot of packing density with change in process variables.

smaller diameter. Also, the lower helix angle with finer lap hank further increases the packing density of the yarn. The increase in card draft (from 88 to 114 card draft) and corresponding decrease in ring frame draft tend to increase the packing density of yarn mainly because of reduction in yarn diameter. Further increase in card draft (from 114 to 127) and corresponding decrease in ring frame draft decrease the packing density. This is due to increase in yarn diameter and increase in helix angle. Increase in draft/doublings increases the packing density due to increase in compactness of fibre band. Decrease in helix angle at higher draft/doublings is also responsible for increase in packing density of yarn. This shows that, in ring yarn, packing density and diameter are inversely related.

Like in ring yarn-type I, the finer lap hank and higher draft/doublings increase the packing density of ring yarn type II. This is mainly due to the decrease in helix angle and yarn diameter. The increase in card draft (from 88 to 101) and corresponding decrease in speed frame draft increases the packing density mainly by reducing the yarn diameter. Further, increase in card draft and corresponding reduction in speed frame draft make the roving and corresponding yarn less compact due to an increase in yarn diameter.

In rotor yarn, increase in card draft and decrease in rotor draft increase the packing density mainly due to an increase in the helix twist and decrease in the yarn diameter, as explained in previous sections. Like in ring yarn, the trends of $\mathrm{S} / \mathrm{N}$ ratio plot of packing density of rotor yarn are similar to those of yarn diameter.

In air-jet yarn, finer lap hank and increase in card draft and corresponding decrease in air-jet draft decrease the yarn packing density by increasing the yarn diameter and helix angle, and reduction in helix twist. The draft/ doublings have no influence on yarn diameter. Overall, the trends of change in $\mathrm{S} / \mathrm{N}$ ratio of packing density in air-jet yarn are similar to those of yarn diameter and helix angle. This implies that decrease in yarn diameter or decrease in helix angle increases the packing density of the yarn

Tables 7 to 8 show that the changes in helix angle, helix twist, yarn diameter and packing density, as analysed by ANOVA technique and ranked by the Taguchi method, are in agreement with each other. Further, the change in above parameters is mainly influenced by change in card draft.

\subsection{Effect of Noise Variables on Packing Density Parame- ters}

\subsubsection{Effect of Doff Position}

Table 9 shows that in ring yarns, the change in doff position has marginal effect on diameter, helix twist, and packing density of two types of ring yarns. However, the trends of doff position on diameter are opposite to the effect on helix twist and packing density. Further, the helix angle decreases with the build of the cop from bottom to top. This opposite trend in yarn diameter and packing density was also reported in the previous section.

In rotor yarns, the fibre extent and fibre overlapping decrease as the package builds up. This is due to the decrease in yarn tension, because the yarn is wind over relatively softer yarn filed cheese at the top. The higher yarn tension at bare hard empty cheese at the bottom causes more tension to permeate at yarn formation zone inside the rotor groove, which may be the reason of higher fibre extent. The peripheral twist extent increases which gives less time to the fibre to integrate in the rotor groove. Thus, fibres have relatively less time available after exit of the doff tube till picked by twisting yarn tail. This ultimately leads to higher helix twist and diameter, but subsequently lower helix angle and packing density of the rotor yarn.

The fibre orientation in well packed air-jet yarn structure hardly changes with doff winding position of the cheese. All the packing density parameters such as yarn diameter, helix 
Table 9. Contribution of Noise Variables to Various Packing Density Parameters

\begin{tabular}{|c|c|c|c|c|c|c|c|c|c|c|}
\hline & & \multicolumn{3}{|c|}{ Doff Position } & \multicolumn{3}{|c|}{ Spindle Position } & \multicolumn{3}{|c|}{ Atmospheric Condition } \\
\hline & & Top & Bottom & $\%$ Effect $*$ & $\mathbf{1}$ & 2 & $\%$ Effect $*$ & UC & $\mathbf{C}$ & $\%$ Effect \\
\hline \multirow{3}{*}{$\begin{array}{c}\text { Helix Angle } \\
\text { (degrees) }\end{array}$} & Ring yarn-type I & 11.6 & 12.4 & -6.7 & 11.7 & 12.2 & -4.6 & 11.5 & 12.4 & -8.2 \\
\hline & Ring yarn-type II & 11.6 & 12.4 & -6.7 & 11.7 & 12.2 & -4.6 & 11.5 & 12.4 & -8.2 \\
\hline & Rotor yarn & 16.1 & 15.2 & 6.2 & 15.5 & 15.8 & -1.9 & 15.6 & 15.7 & -1.0 \\
\hline \multirow{3}{*}{$\begin{array}{c}\text { Helix Twist } \\
\text { (per inch) }\end{array}$} & Ring yarn-type II & 15.6 & 15.2 & 3.2 & 15.6 & 15.2 & 2.1 & 16.5 & 14.3 & 13.8 \\
\hline & Rotor yarn & 19.4 & 20.0 & -2.7 & 19.3 & 20.1 & -4.1 & 20.7 & 18.7 & 10.4 \\
\hline & Air-jet yarn & 17.9 & 17.8 & 0.8 & 18.4 & 17.3 & 6.1 & 18.0 & 17.6 & 2.02 \\
\hline \multirow{2}{*}{$\begin{array}{c}\text { Diameter } \\
(1 / 100 \mathrm{~mm})\end{array}$} & Ring yarn-type I & 19.6 & 19.5 & 0.5 & 19.2 & 19.8 & -3.0 & 19.2 & 19.8 & -3.5 \\
\hline & Air-jet yarn & 19.0 & 19.3 & -1.1 & 18.7 & 19.6 & -4.3 & 18.9 & 19.4 & -3.1 \\
\hline \multirow{4}{*}{ Packing Density } & Ring yarn-type I & 0.544 & 0.550 & -1.1 & 0.564 & 0.531 & 6.0 & 0.567 & 0.527 & 7.31 \\
\hline & Ring yarn-type II & 0.561 & 0.541 & 3.6 & 0.567 & 0.535 & 5.8 & 0.554 & 0.547 & 1.27 \\
\hline & Rotor yarn & 0.470 & 0.416 & 12.2 & 0.441 & 0.446 & -1.2 & 0.427 & 0.460 & -7.54 \\
\hline & Air-jet yarn & 0.574 & 0.559 & 2.5 & 0.591 & 0.542 & 8.8 & 0.584 & 0.546 & 6.68 \\
\hline
\end{tabular}

$\%$ effect for a variable is $=$ (response value in I column - response value in II column $)$ 100/ mean of both values.

twist and packing density change marginally with the change in cheese winding position.

\subsubsection{Effect of Spindle Position}

The change in spindle position also changes packing density parameters, such as, diameter, helix angle, helix twist, and packing density. However, the spinning conditions at various spindle position depend on mechanical conditions of various mechanical parts. The effects of those parameters are difficult to figure out. But, the data confirms that there are some changes in the results with the change in spindle position, which is uncontrollable.

\subsubsection{Effect of Material Conditioning before Testing}

In ring yarns, the laboratory conditioning at standard humidity and temperature increases yarn diameter, and fibre helix angle and decrease helix twist in the yarn. Consequently, the packing density of the ring yarn also decreases. In rotor yarn, the diameter and helix twist decrease with conditioning which leads to an increase in packing density of the ultimate yarn. In air-jet yarn, the yarn boundary becomes wavier upon relaxation due to high transverse stresses of the wrappers. Subsequently, diameter increases and packing density decreases in the air-jet yarn structure.

The analysis of noise factors effect on fibre orientation and yarn properties shows that there are variations in the results due to change in noise factors. When the \% effect due to noise factors was compared with \% effect due to controllable factors, it is revealed that the changes in noise factors cause considerable changes in responses, in some of the cases. Overall, it is imperative to study the effect of these noise variables.

\section{CONCLUSIONS}

1. The yarn diameter is the highest and the packing density the least in rotor yarn. The yarn diameter is the least and the packing density the highest in air-jet yarn. Packing density is inversely related to the diameter of ring, rotor and, air-jet yarns.

2. The packing density of ring yarn tends to increase with the decrease in helix angle and packing density of air-jet yarn tends to increase with an increase in helix twist.

3. The change in card draft influences most of the changes in helix angle, helix twist, yarn diameter, and packing density.

4. Change in doff position from bottom to top in ring yarn causes decrease yarn diameter but increases the packing density.

5. Atmospheric conditioning in ring yarn increases yarn diameter, but decreases packing density.

6. Analysis of spinning process using Taguchi method brings out the effect of variables from a stage of perception to irrefutable definitive quantified effect of variables on response. These findings are in accordance with some of the previous researchers.

\section{ACKNOWLEDGEMENTS}

Authors acknowledge the help and guidance of Prof. S. G. Deshmukh, Department of Mechanical Engineering, Indian Institute of Technology, Delhi, India, in successfully carrying out the experiments and analysis of the results. 
Authors are also grateful to The Orient Syntex Ltd., The Bhaskar Spinning Mills Ltd., The Mahavir Spinning Mills Ltd., and The TIT Spinning Mills Ltd. for providing the necessary facilities for preparation and testing of the research samples.

\section{REFERENCES}

[1] T. P Bagchi, Taguchi methods explained. Practical steps to Robust Design, Prentice Hallof India Private Limited, New Delhi, 1993.

[2] Available from: http://en.wikipedia.org/wiki/Taguchi_method.

[3] M. S. Padhke, "Introduction to Robust Design". Available: http://www.isixsigma.com/library/content/c020311a.asp.

[4] I. Bass, "Introduction to Taguchi Methods-Part I". Available: http://www.sixsigmafirst.com/intro2 taguchi1.htm.

[5] I. Bass, "Introduction to Taguchi Methods-Part II". Available: http://www.sixsigmafirst.com/intro2 taguchi1.htm.

[6] G. Holt and W. Laird, "Screening for optimal parameters for the powered roll gin stand using Taguchi's Robust Designh", J. Cotton Sci., vol. 11, pp. 79-90, 2007.

[7] T. Ramachandran and D. Saravanan, "Improving products and processes: Taguchi Methods Demystified”, Indian Text. J., pp. 2330, June 2008 .

[8] K. R. Salhotra, S. M. Ishtiaque, and A. Kumar, "Analysis of spinning process using taguchi method, Part I: Effect of spinning process variables on fibre orientation in sliver and roving", J. Text. Inst., vol. 97, no. 3, pp. 271-283, 2006.

[9] S. M. Ishtiaque, K. R. Salhotra, and A. Kumar, "Analysis of spinning process using taguchi method Part II: Effect of spinning process variables on fibre extent and fibre-overlap in ring, rotor and airjet yarns", J. Text. Inst., vol. 97, no. 4, pp. 285-293, 2006.

[10] A. Kumar, S. M. Ishtiaque, and K. R. Salhotra, "Analysis of spinning process using taguchi method Part III: Effect of spinning process variables on migration parameters of ring, rotor and air-jet yarn", J. Text. Inst., vol. 97, no. 5, pp. 377-384, 2006.
[11] Kumar, S. M. Ishtiaque, and K. R. Salhotra "Analysis of spinning process using taguchi method Part IV: Effect of spinning process variables on tensile properties of ring, rotor and air-jet yarns", $J$. Text. Inst., vol. 97, no. 5, pp. 385-390, 2006.

[12] A. Kumar, K. R. Salhotra and S. M. Ishtiaque "Analysis of spinning process using Taguchi method Part V: Effect of spinning process variables on physical properties of ring, rotor and air-jet yarns", $J$. Text. Inst., vol. 97, no. 6, pp. 463-473, 2006.

[13] C. J. Webb, G.T. Waters, A.J. Thomas, and G. P. Liu, "The use of the Taguchi Design of experiment method in optimizing splicing conditions for a Nylon 66 Yarn", J. Text. Inst., vol. 98, pp. 327-336, 2007.

[14] C.P. Fung and P.C. Kang, “ Multi-response optimisation in friction properties of PBT composite using Taguchi Method and principal component analysis", J. Mater. Process. Technol., vol. 170, pp. 602 $-610,2005$.

[15] O. Yeniay, "A comparison of the performance between a gnetic algorithm and the Taguchi method over artifical problem", Turkish J. Engg. Environ. Sci., vol. 25, pp. 561-568, 2001.

[16] S. Ray, “ A statistical tool for process optimisation", Indian Text. J., pp. 24-30, Dec. 2006.

[17] S. M. Ishtiaque, "Selected problems of internal structure of rotorspun yarn", Ph.D. thesis, University of Mechanical and Textile Engineering, Liberec, Czechoslovakia, 1983.

[18] W. E. Morton, and R. J. Summers, "Fibre Arrangement in card sliver", J. Text. Inst., vol. 40, p. 106, 1949.

[19] J. Y. Ha, and C. K. Park, "Optimisation of sewing conditions for seam pucker using taguchi method", Conference CD proceedings of $7^{\text {th }}$ Asian Textile Conference (Textile Association India, New Delhi) 2003.

[20] S. M. Ishtiaque, "Distribution of fibres in cross-section of rotor- and ring- spun yarns and their strength", Indian J. Text. Res., vol. 11, p. $215,1986$.

[21] S. M. Ishtiaque, K. Dhawan, A. Saxena, and J. Parkesh, "Siro yarn mechanics", Text. Asia, p. 118, September 1988.

[22] S. M. Ishtiaque, I. C. Sharma, and S. Sharma, "Structural mechanics of Siro yarn by microtomy", Indian J. Fibre Text. Res., vol. 18, pp. 116-119, 1993

(C) Kumar et al.; Licensee Bentham Open .

This is an open access article licensed under the terms of the Creative Commons Attribution Non-Commercial License (http://creativecommons.org/licenses/bync/3.0/), which permits unrestricted, non-commercial use, distribution and reproduction in any medium, provided the work is properly cited. 